\title{
Hyperbaric oxygen and topical oxygen are different treatments
}

\begin{abstract}
Sir,
We read with interest the article named 'pressure ulcers: Current understanding and newer modalities of treatment' that was published in Indian J Plast Surgery 2015 January-April issue. We thought that there was a misunderstanding in hyperbaric oxygen therapy (HBOT) definition. They have defined HBOT based on reference number $47^{[1]}$ which actually is the definition of topical oxygen treatment (TOT). Then, they have explained the effects of HBOT based on the reference number $49^{[2]}$ in the same section.
\end{abstract}

Hyperbaric oxygen is a treatment, in which a patient breathes near $100 \%$ oxygen intermittently while inside a treatment chamber at a pressure higher than sea level pressure (i.e., $>1$ atmosphere absolute; atm abs). Current information indicates that pressurisation should be to $1.4 \mathrm{~atm}$ abs or higher. ${ }^{[3]}$ On the other hand, with TOT an airtight chamber or polyethylene bag is sealed around a limb or the trunk by either a constriction/tourniquet device or by tape and high flow (usually $10 \mathrm{~L} / \mathrm{min}$ ) oxygen is introduced into the bag and over the wound. Pressures just over $1.0 \mathrm{~atm}$ abs (typically 1.004-1.013 atm abs) are recommended because higher pressures could decrease arterial/ capillary inflow. ${ }^{[4]}$

In order to avoid this confusion, UHMS (Undersea \& Medical Hyperbaric Society) published a position statement. As explained in UHMS position statement on topical oxygen; frequently, and erroneously, this form of oxygen administration has been referred to as 'topical HBOT' or even more erroneously 'HBOT'. The policy of the UHMS in regard to topical oxygen is stated as follows:

1. Topical oxygen should not betermed hyperbaric oxygen since doing so either intentionally or unintentionally suggests that TOT is equivalent or even identical to hyperbaric oxygen. Published documents reporting experience with topical oxygen should clearly state that topical oxygen, not hyperbaric oxygen is being employed. 
2. Mechanisms of action or clinical study results for hyperbaric oxygen cannot and should not be co-opted to support topical oxygen since HBOT and topical oxygen have different routes and probably efficiencies of entry into the wound and their physiology and biochemistry are necessarily different. ${ }^{[4]}$

\title{
Financial support and sponsorship
}

Nil.

\section{Conflicts of interest}

There are no conflicts of interest.

\section{Ozturk Handan, Aktas Samil}

Faculty of Medicine, Istanbul University, Departure of Underwater and Hyperbaric Medicine, Istanbul, Turkey

\author{
Address for correspondence: \\ Dr. Handan Ozturk, Faculty of Medicine, \\ Istanbul University, Istanbul, Turkey. \\ E-mail: drhandanozturk@gmail.com
}

\section{REFERENCES}

1. Fischer $\mathrm{BH}$. Topical hyperbaric oxygen treatment of pressure sores and skin ulcers. Lancet 1969;2:405-9.

2. Bhutani S, Vishwanath $\mathrm{G}$. Hyperbaric oxygen and wound healing. Indian J Plast Surg 2012;45:316-24.

3. UHMS. Hyperbaric Oxygen Therapy Indications. $13^{\text {th }}$ ed. 2014, UHMS; USA.

4. Feldmeier JJ, Hopf HW, Warriner RA rd, Fife CE, Gesell LB, Bennett M. UHMS position statement: Topical oxygen for chronic wounds. Undersea Hyperb Med 2005;32:157-68.

This is an open access article distributed under the terms of the Creative Commons Attribution-NonCommercial-ShareAlike 3.0 License, which allows others to remix, tweak, and build upon the work non-commercially, as long as the author is credited and the new creations are licensed under the identical terms.

\begin{tabular}{|l|l|}
\hline \multicolumn{2}{|c|}{ Access this article online } \\
\hline Quick Response Code: & Website: \\
\hline & www.ijps.org \\
\cline { 2 - 2 } & \\
\hline
\end{tabular}

How to cite this article: Handan O, Samil A. Hyperbaric oxygen and topical oxygen are different treatments. Indian J Plast Surg 2015;48:216-7. 